\title{
GIS-based Numerical Modelling of Debris Flow Motion across Three-dimensional Terrain
}

\author{
WU Jian, CHEN Guang-qi, ZHENG Lu, ZHANG Ying-bin* \\ Department of Civil and Structure Engineering, Faculty of Engineering, Kyushu University, Fukuoka 819-0395, Japan \\ First author, e-mail: wujiancome@sina.com; Tel: +81 o8o 4281 8411; Address: Geo-disaster Prevention Laboratory, West \\ 2-1110, 744 Motooka, Nishi-ku, Fukuoka, 819-o395, Japan \\ *Corresponding author, e-mail:yingbinz719@126.com; Tel: +81 o80 3227 3954; Address: Geo-disaster Prevention \\ Laboratory, West 2-1110, 744 Motooka, Nishi-ku, Fukuoka 819-o395, Japan
}

(C) Science Press and Institute of Mountain Hazards and Environment, CAS and Springer-Verlag Berlin Heidelberg 2013

\begin{abstract}
The objective of this study is to incorporate a numerical model with GIS to simulate the movement, erosion and deposition of debris flow across the three dimensional complex terrain. In light of the importance of erosion and deposition processes during debris flow movement, no entrainment assumption is unreasonable. The numerical model considering these processes is used for simulating debris flow. Raster grid networks of a digital elevation model in GIS provide a uniform grid system to describe complex topography. As the raster grid can be used as the finite difference mesh, the numerical model is solved numerically using the Leap-frog finite difference method. Finally, the simulation results can be displayed by GIS easily and used to debris flow evaluation. To illustrate this approach, the proposed methodology is applied to the Yohutagawa debris flow that occurred on 20th October 2010, in AmamiOshima area, Japan. The simulation results that reproduced the movement, erosion and deposition are in good agreement with the field investigation. The effectiveness of the dam in this real-case is also verified by this approach. Comparison with the results were simulated by other models, shows that the present coupled model is more rational and effective.
\end{abstract}

Key words: Debris flow; Numerical simulation; GIS; Movement; Erosion; Deposition; Equilibrium concentration

Received: 13 August 2012

Accepted: 28 February 2013

\section{Introduction}

Debris flow is a rapid flow which may lead to severe flooding with catastrophic consequences such as damage to properties and loss of human lives. For example, in the 'Minamarta debris flow disaster' in 2003, 21 people were killed by the debris flow. Two hundred houses, many office buildings and the Hakata-eki subway station were inundated with muddy water (Sidle and Chigira 2004). More recently, a giant debris flow burst on August 8th, 2010 in Zhouqu City, China, killing 1,765 people. More than 5,500 houses were inundated and the total economic losses reached 212 million RMB (Chinese Yuan) (Tang et al. 2011). Therefore, debris flow disasters have been recognized as a critical problem today and increasing attention has been focused on the study of debris flows.

Debris flows consist of sediment and water mixture moving as a highly mobile, continuous fluid flow driven by gravity. There is often significant erosion and deposition associated with debris flow movement that can dramatically change the channel bed. At the beginning of the fan, where the slope of the bed decreases significantly, debris flow slows significantly, depositing large amounts of sediments (Armanini et al. 2009).

Due to the complexity of the debris flow process, a number of models have been developed 
to simulate movement behavior of debris flow. These models can be classified as either: singlephase models (Hungr 1995; Hungr and Evans 1997; Naef et al. 1999; Rickenmann and Koch 1997; Coussot 1994; Whipple 1997), or two-phase models (Brufau et al. 2000; Nakagawa et al. 1997, 2000; Shieh 1996; Takahashi 1991; Takahashi et al. 1992; Zanre and Needham 1996; Lai 1991; Morris and Willians 1996; Quan et al. 2011, 2012). Singlephase models are often used in situations with no significant morphological changes. These integrated models present only the volume conservation and momentum equations. They have the advantage to obtain the parameters from current debris flows. However, they cannot simulate the important erosion and deposition process. The two-phase models treat the solid and fluid separately and the integrated model presents one momentum equation, derived for a fluid with the bulk density. The equations, which describe the flow, are completed by a mass conservation equation for each of the two phases (Fraccarollo and Papa 2000). Two-phase models permit a nonhomogeneous treatment of the mixture. They can simulate the erosion and deposition processes through the movable channel bed. Two-phase models are suitable to solve problems where the morphological evolution is to be determined. In this study, we adopted the more favored Takahashi model which incorporated the possibility of erosion and deposition.

For hazard mapping and risk assessment, the geographic information system (GIS) has been recognized as a useful tool to process spatial data and to display results. The GIS-based approaches in assessing debris flow developed by Lin and Jeng 1995; Cheng et al. 1997; Lin et al. 1998, Lin et al. 2000, Kappes et al. 2011, and Blahut et al. 2011 allows numerical simulation by incorporating GIS and provides important prediction and analysis tools. One significant advantage of numerical simulation coupled with GIS is that the grid networks for simulation can be extracted from GIS raster data and all the calculated results displayed in GIS can be used for direct debris flow evaluation.

In this study, we adopted the flow dynamic model from Takahashi et al. (1992) (referred as Tmodel hereafter) and developed a debris flow simulation program incorporating with GIS by deriving the computation networks from GIS raster data. To illustrate the advantage of this approach, we used it to simulate a well-documented Yohutagawa debris flow in Japan.

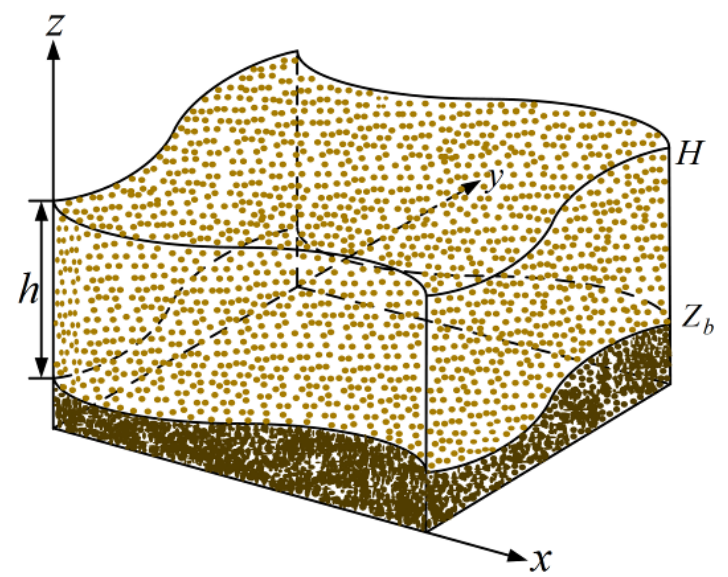

Figure 1 Definition of coordinate system for two dimensional governing equations

\section{Description of Numerical Model}

\subsection{Governing equations}

Debris flow is treated as a two-phase mixture flow of solid and fluid in the T-model. An important feature of this model lies in considering the dynamics of the mixture and the morphological evolution of the river bed. The depth-averaged partial differential equations of the T-model are derived from the conservation balances of mass (solid and mixture) and of momentum (mixture) in a coordinate system (Figure 1). The detail deduced process is based on the work of Takahashi et al. (1986). The governing equations describing the process of debris flow may be described as follows.

The depth averaged momentum conservation equations in $x$ - and $y$-directions are respectively given as:

$$
\begin{aligned}
& \frac{\partial M}{\partial t}+\beta \frac{\partial(u M)}{\partial x}+\beta \frac{\partial(v M)}{\partial y}=-g h \frac{\partial\left(h+Z_{b}\right)}{\partial x}-\frac{\tau_{b x}}{\rho_{d}} \text { (1) } \\
& \frac{\partial N}{\partial t}+\beta \frac{\partial(u N)}{\partial x}+\beta \frac{\partial(v N)}{\partial y}=-g h \frac{\partial\left(h+Z_{b}\right)}{\partial y}-\frac{\tau_{b y}}{\rho_{d}} \text { (2) }
\end{aligned}
$$

The continuity Eq.of debris flow mixture is:

$$
\frac{\partial h}{\partial t}+\frac{\partial M}{\partial x}+\frac{\partial N}{\partial y}=i
$$

The continuity equation of the solid fraction is:

$$
\frac{\partial(C h)}{\partial t}+\frac{\partial(C M)}{\partial x}+\frac{\partial(C N)}{\partial y}=i \cdot C_{b}
$$


The equation for the change of river bed elevation is:

$$
\frac{\partial Z_{b}}{\partial t}=-i
$$

where $M=u h$ and $N=v h$ are the flow flux components in $x-$ and $y-$ directions, respectively; $u$ and $v$ are the depth-averaged velocity components in $x$ - and $y$-directions, respectively; $h$ is the flow depth; $Z_{b}$ is the vertical bottom coordinate of the channel bed; $\beta$ is the quadratic correcting coefficient taking into account the shape of the velocity profile; $\rho_{d}$ is the debris flow mixture density, and $\rho_{d}=C(\sigma-\rho)+\rho, \sigma$ and $\rho$ are the solid density and fluid density, respectively; $C$ and $C_{b}$ are the volume concentration of solids fraction in the flow and on the bed, respectively; $g$ is the gravitational acceleration; $i$ is the erosion or deposition velocity; $\tau_{b x}$ and $\tau_{b y}$ are the bottom resistance on the river bed in $x$ - and $y$-directions, respectively.

\subsection{Implementation of erosion and deposition}

To complete the five equations above, two closure equations are needed for computing the velocity of erosion or deposition and the bottom resistance. According to the empirical equations of Takahashi (2007), the velocity of erosion or deposition in Eqs.(3) (4) and (5) can be written as follows.

When erosion $\left(C<C_{\infty}\right)$ :

$$
i=\delta_{e} \frac{C_{\infty}-C}{C_{b}-C_{\infty}} \frac{\sqrt{u^{2}+v^{2}} h}{d}
$$

When deposition $\left(C>C_{\infty}\right)$ :

$$
i=\delta_{e} \frac{C_{\infty}-C}{C_{b}} \frac{\sqrt{u^{2}+v^{2}} h}{d}
$$

where $\delta_{e}$ and $\delta_{d}$ are the erosion and deposition coefficient, respectively; $d$ is the represent diameter. $C_{\infty}$ is the equilibrium concentration and can be represented as follows (Nakagawa et al. 2003):

If QUOTE $\tan \theta \geq \tan \varphi, C_{\infty}=0.9 C_{b}$

If QUOTE $\tan \varphi>\tan \theta>0.138$,

$$
C_{\infty}=\frac{\rho \tan \theta}{(\sigma-\rho)(\tan \varphi-\tan \theta)}
$$

If QUOTE $\quad 0.138 \geq \tan \theta>0.03$,

$$
C_{\infty}=6.7\left[\frac{\rho \tan \theta}{(\sigma-\rho)(\tan \varphi-\tan \theta)}\right]^{2}
$$

If QUOTE $\tan \theta \leq 0.03$,

$C_{\infty}=\frac{(1+5 \tan \theta) \tan \theta}{\sigma / \rho-1}\left(1-\alpha_{c}{ }^{2} \frac{\tau_{* c}}{\tau_{*}}\right)\left(1-\alpha_{c} \sqrt{\frac{\tau_{*_{c}}}{\tau_{*}}}\right)$

In which,

$$
\begin{aligned}
\tau_{* c} & =0.04 \times 10^{1.72 \tan \theta} \\
\alpha_{c}^{2} & =\frac{2\left(0.425-\frac{\sigma \tan \theta}{\sigma-\rho}\right)}{1-\frac{\sigma \tan \theta}{\sigma-\rho}} \\
\tau_{*} & =\frac{\rho}{\sigma-\rho} \frac{h \tan \theta}{d}
\end{aligned}
$$

where $\theta$ is the slope angle; $\varphi$ is the Coulomb or basal friction angle. $\tau_{* c}$ is the non-dimensional critical shear stress, and $\tau_{*}$ is the non-dimensional shear stress.

\subsection{Bottom resistance laws}

One of the most important parts of the model is the incorporation of different rheological flow behaviors. The bottom resistance $\tau_{b x}$ and $\tau_{b y}$ in Eqs.(1) and (2) are described as follows.

For stony-type debris flow $\left(C \geq 0.4 C_{b}\right)$ :

$$
\tau_{b x}=\frac{\rho_{d} u \sqrt{u^{2}+v^{2}} d^{2}}{8 h^{2}\left[C+(1+C)\left(\rho_{d} / \sigma\right)\right]\left[\left(C_{b} / C\right)^{1 / 3}-1\right]^{2}}
$$

For immature debris flow $\left(0.01 \leq C \leq 0.4 C_{b}\right)$ :

$$
\tau_{b x}=\frac{\rho_{d} u \sqrt{u^{2}+v^{2}} d^{2}}{0.49 h^{2}}
$$

For bed load transportation ( $C \leq 0.01)$ :

$$
\tau_{b x}=\frac{\rho_{d} g n_{m}{ }^{2} u \sqrt{u^{2}+v^{2}}}{h^{1 / 3}}
$$

where $n_{m}$ is pseudo-Manning's coefficient which accounts for both turbulent boundary friction and internal collisional stress. $d$ is representative diameter.

\subsection{Stop condition}

In this study, we use a simple stop condition of debris flow in deposition area (Takahashi et al. 1987): 


$$
\sqrt{u^{2}+v^{2}} \leq U_{T H}
$$

\section{Numerical Simulation Coupled With GIS}

In this section, we show how to produce numerical simulation incorporating GIS technology.

\subsection{Generation of DEM for simulation}

In order to generate the topographical data required for the simulation using T-model, we use GIS to generate DEM for simulation. Three schemes for structuring elevation data for DEMs are: triangulated irregular networks (TIN), grid networks, and vector or contour-based networks (Moore and Grayson 1991). The most widely used data structures are square grid networks with rows and columns where each cell contains a value such as elevation (Figure 2b). The grid based discretization of the study area is immensely useful for numerical solution of the partial differential equations governing the propagation of debris flows. Finite-difference methods on rectangular grids are widely used in numerical models of environmental flows when using this method, the studied region is discretized into rectangular grids. Therefore, in this paper, we used the rectangular grid networks from GIS for finite difference method.

\subsection{Source identification and upstream boundary setting}

Next step is to identify the initiation area of debris flow. After field investigation in the area and after studying the available aerial photographs, the source zone boundary can be identified by GIS. It is labeled as yellow shaded area as denoted in Figure 2b. According to field observation an approximate total volume of source zone soil that may be available. So the average thickness of slide discharge in initiation area is estimated from the soil volume in initiation area divided by its area, and we can set the initial concentration based on investigation of source zone. This average thickness and initial concentration in the initiation area of debris flow are used as the upstream boundary for numerical simulation.

\subsection{Numerical solution and results display}

The Takahashi model is solved in rectangular grid networks from GIS. The flow direction of a cell is expressed in degrees: left $=0^{\circ}, \quad \mathrm{up}=90^{\circ}$, right $=180^{\circ}$, down $=270^{\circ}$; and the diagonals: $45^{\circ}$, $135^{\circ}, 225^{\circ}, 315^{\circ}$. Within a cell, overland flow is routed along one flow direction. The flow direction is the maximum downslope direction which is determined from the raster-based DEM (Figure 2a). The numerical solution of the above Eq. (1) to (5) is based on a leap-frog difference scheme that is accurate in space and time, the linear terms use forward difference scheme, and the nonlinear terms use central difference scheme. As denoted in Figure 2c, the flow depth, concentration or elevation of the debris flow mass in each grid is arranged at the midpoint, and the flux $M$ and $N$ are arranged at the central point of the grid boundary. These specific difference equations were derived by means of explicit staggered leap-frog
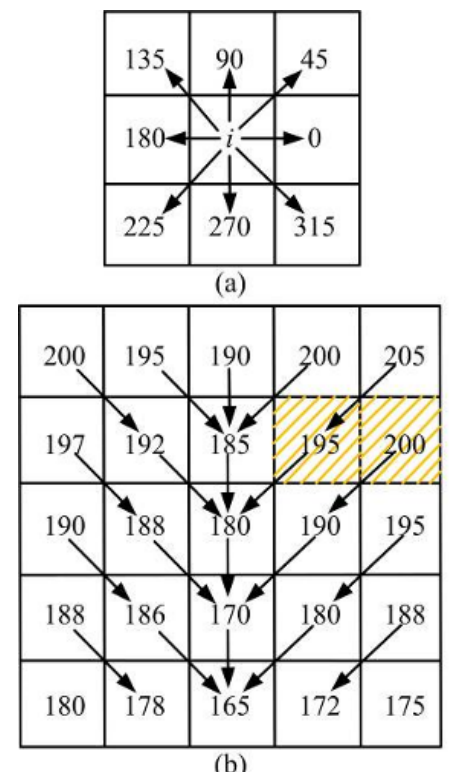

(b)

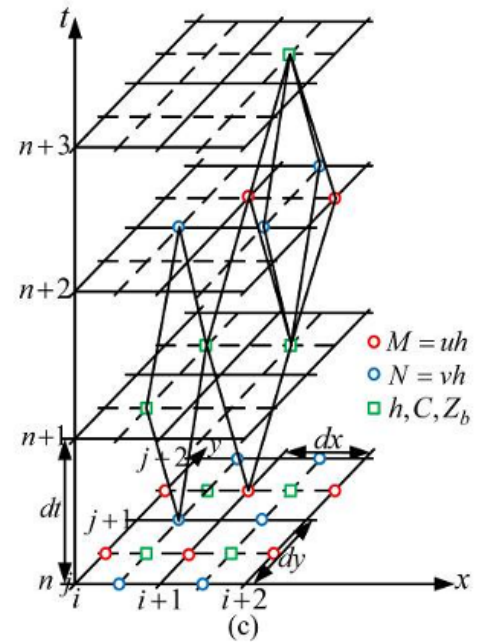

(c)

Figure 2 Leap-frog finite difference formulation based on the DEM grid (a) Possible flow direction in a cell; (b) Flow direction in a DEM; (c) Grids and flow for debris flow computation 
scheme proposed by Yoshiaki and Akihide (1988). Finally, these five equations have been coded by $C++$ language. All the input and output data are processed in ArcGIS. The tool is embedded in a GIS to simplify the input data such as the DEM and to help the interpretation of numerical simulation results.

\section{Case Study}

\subsection{Outline}

To verify the model and illustrate its validation, the model is applied to a real debris flow that occurred in Japan. Many landslides were triggered by the heavy rainfalls in the Amami-Oshima Island, Kagoshima Prefecture, in October, 2010. Especially, the 2010 rainfall at Amami city from October 18th to 21st was the highest recorded torrential downpour in a century. The landslide and resultant debris flow at $\left(28^{\circ} 24^{\prime} \mathrm{N}, 129^{\circ} 31^{\prime} \mathrm{E}\right)$ was the largest of the October disasters in AmamiOshima area (Figure 3). The debris flow occurred 6 hours after the beginning of the rainstorm, at 12:00 am on 2oth October 2010, during the time of highest rainfall intensity. The debris flow initiated from highly weathered andesite. The debris flow began after the landslide entered residential area and moved about $1.1 \mathrm{~km}$ along the channel. The gradient of the channel was about $17^{\circ}-9^{\circ}$, and the

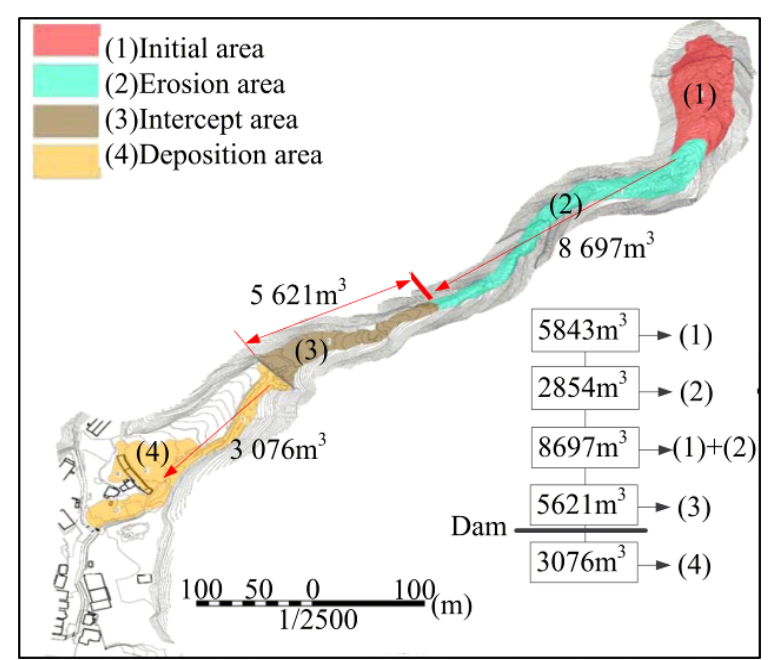

Figure 4 Actual movement of sediment (Photograph modified from the report of KKG)

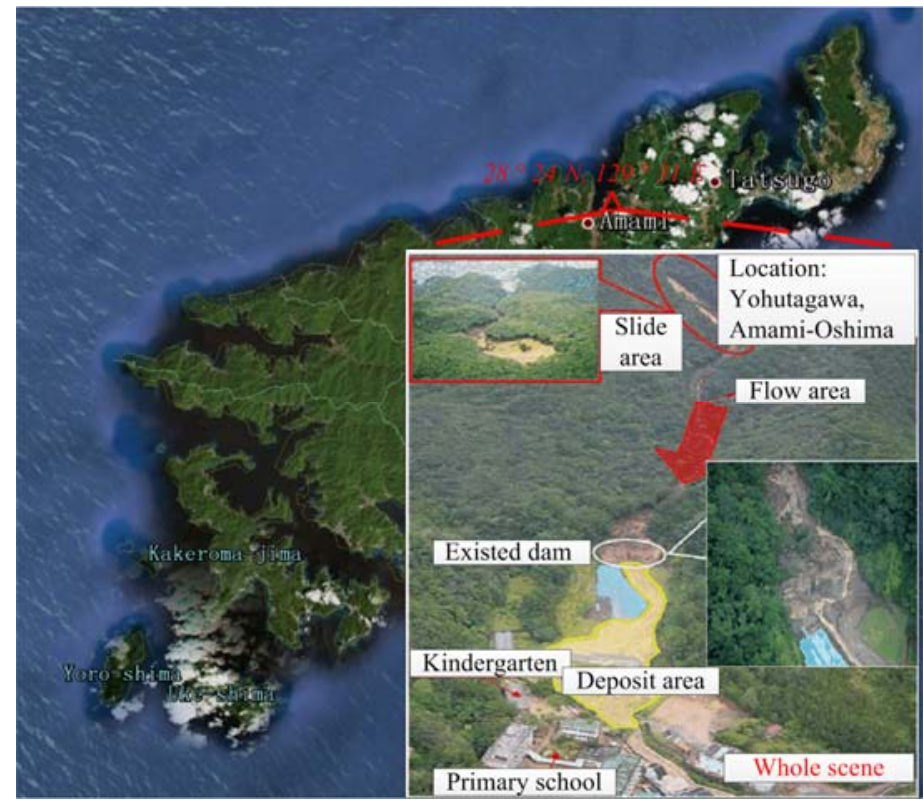

Figure 3 Photograph of Yohutagawa debris flow (modified from KKG's photograph), Japan

mean gradient of the fan was about $5^{\circ}$. Because of an existing dam in its path this debris flow only destroyed one building and one house. The kindergarten and primary school were not affected by this disaster (Figure 3).

\subsection{Field investigation}

According to the investigation by the Kokusai Kogyo Group (KKG) who study geological hazard surveys, the actual movement of sediment is shown in Figure 4, we can see that the total volume in initial and erosion area was approximately 8,697 $\mathrm{m}^{3}$, the volume in intercept area by dam was about $5,621 \mathrm{~m}^{3}$, and the volume rush out of the dam in deposition area was about 3,076 $\mathrm{m}^{3}$. The specific location of each area is also shown in Figure 4.

\subsection{Source identification and parameter determination}

Based on a topographic map 1/2,500 in scale, a vector contour line file was generated, with vertical spacing of $2 \mathrm{~m}$. This file was converted to TIN (Triangulated Irregular Network), and subsequently DEM (Digital Elevation Model) in ArcGIS (Figure 5). The DEM resolution is $2.5 \mathrm{~m} \times$ $2.5 \mathrm{~m}$. According to field work in the area and after studying the available aerial photographs, the source zone was identified as blue color in Figure 6. 
Because the volume of sediment discharge in the source zone was estimated to be $5,843 \mathrm{~m}^{3}$ and the source zone area was about $3,895 \mathrm{~m}^{3}$, thus the average thickness of discharge was estimated $1.5 \mathrm{~m}$ from the soil volume in initiation area divided by its area, In this simulation, the average thickness $1.5 \mathrm{~m}$ and the concentration 0.44 given by KKG were used as the upstream boundary of simulation. The other material properties and rheological parameters well-documented by the investigation of KKG for simulation are listed in Table 1.

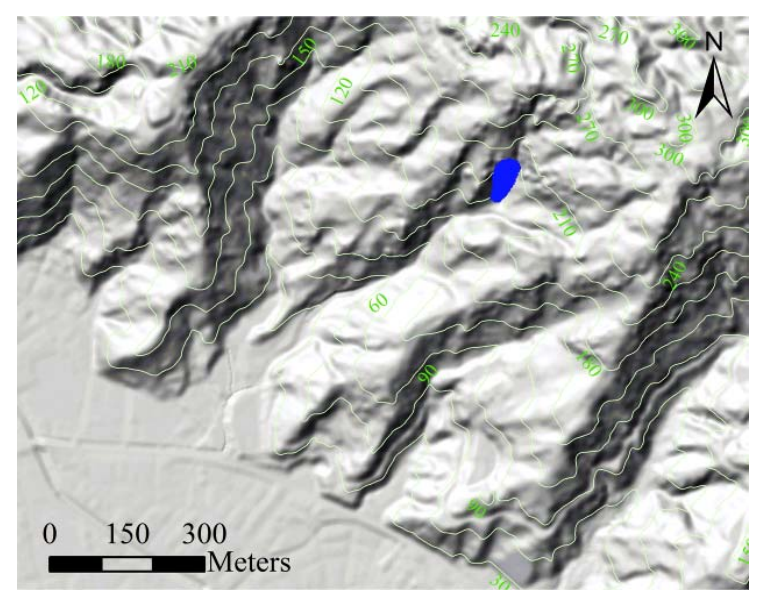

Figure 5 DEM and source zone

Table 1 Material properties and rheological parameters for simulation

\begin{tabular}{|l|l|}
\hline Parameters & Value \\
\hline Solid density: $\sigma\left(\mathrm{kg} / \mathrm{m}^{3}\right)$ & 2,550 \\
\hline Fluid density: $\rho\left(\mathrm{kg} / \mathrm{m}^{3}\right)$ & 1,180 \\
\hline Volume concentration of river bed: $C_{b}$ & 0.60 \\
\hline Representative diameter: $d(m)$ & 0.03 \\
\hline Gravitational acceleration: $g\left(m / s^{2}\right)$ & 9.8 \\
\hline Erosion coefficient: $\delta_{e}$ & 0.0007 \\
\hline Deposition coefficient: $\delta_{d}$ & 0.05 \\
\hline Friction angle: $\varphi$ & 28 \\
\hline Pseudo-Manning's coefficient: $n_{m}$ & 0.04 \\
\hline Time interval: $\Delta t(s)$ & 0.001 \\
\hline Mesh size: $\Delta x=\Delta y(m)$ & 2.5 \\
\hline Velocity of stop condition: $U_{T H}(m / s)$ & 0.4 \\
\hline
\end{tabular}

\section{Results and Discussions}

The results of numerical simulations displayed in GIS provided a time-lapse simulation of the movements and affected regions of debris flow over the three-dimensional complexity terrain (Figure 6). The simulation results show that it took about 214 seconds to move $1.1 \mathrm{~km}$ along the channel at an average flow velocity of $5.14 \mathrm{~m} / \mathrm{s}$. The affected region was dynamically displayed again at different time. Figure 7 shows the recalculated area and bed variation of this debris flow, and we can see that the maximum erosion depth and maximum deposition depth were $1.47 \mathrm{~m}$ and $1.9 \mathrm{~m}$, respectively, and the volume in each area could be calculated in GIS. Comparing with field investigation (Figure 4), we see that each area has good agreement in terms of both location and volume. It shows that the present model based on GIS which considered erosion and deposition is effective and rational. In order to evaluate the effectiveness of the existing dam, the case where the dam did not exist was modeled. The flooded area and the variation of river bed without the dam are shown in Figure 8 (a), and show that the deposit area without dam, 2,150 $\mathrm{m}^{2}$, is much larger than that of case with the dam, $820 \mathrm{~m}^{2}$. This result explains that the existing dam was very important to reduce this debris flow. We also tested the use of different dam heights and showed that the dam height must be increased by $1.62 \mathrm{~m}$ (Figure $8 \mathrm{~b}$ ).

In this study, we used the equilibrium concentration fitting curve from the Takahashi experiments (Takahashi 1982) to simplify Equations (8), (9), (10) and (11) (Figure 9), and derived Eq.(15) as follow:

$$
C_{\infty}=0.0048 \theta^{1.7078}
$$

Using this simple equation, the simulated result (Figure 10), was compared with that used by Nakagawa et al. (2003) (Figure 7), we showed that this simple equation is also useful for simulation and easier to use.

Using the fixed bed model (Wang et al. 2008), which does not consider the erosion and deposition (Figure 11), we could only simulate the thickness of deposit in one time step, but could not simulate the morphological variations, hence the result did not agree with the actual situation. Figure 12 shows the results simulated by using the New-SASS model developed by Sabo and Landslide Technical Center in Japan named. All the comparisons of calculated results are listed in Table 2. We can see that the present coupled model is more reliable than either the fixed bed model or New-SASS model. 


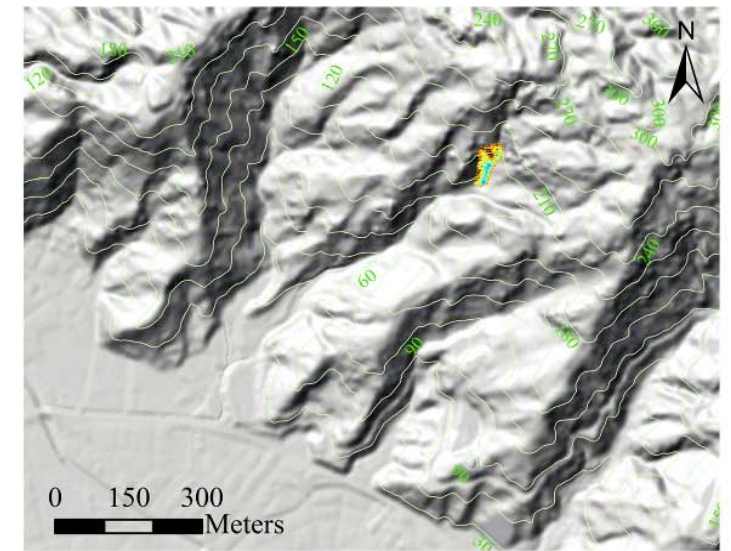

(a)

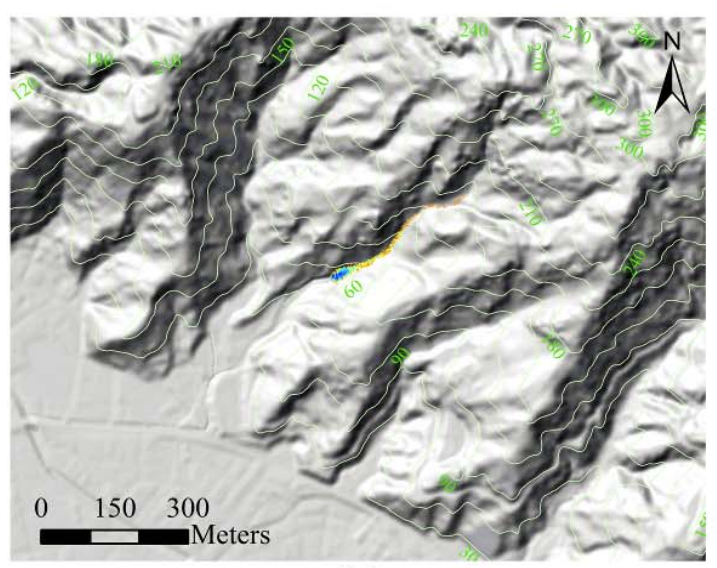

(c)

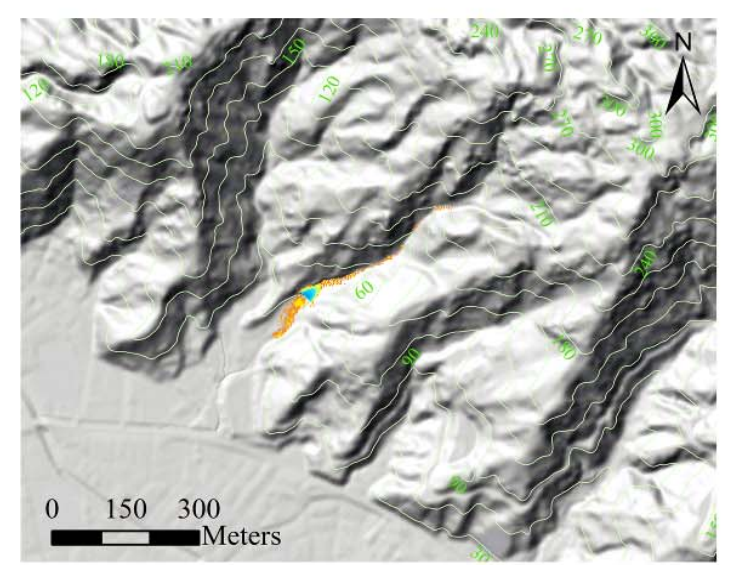

(e)

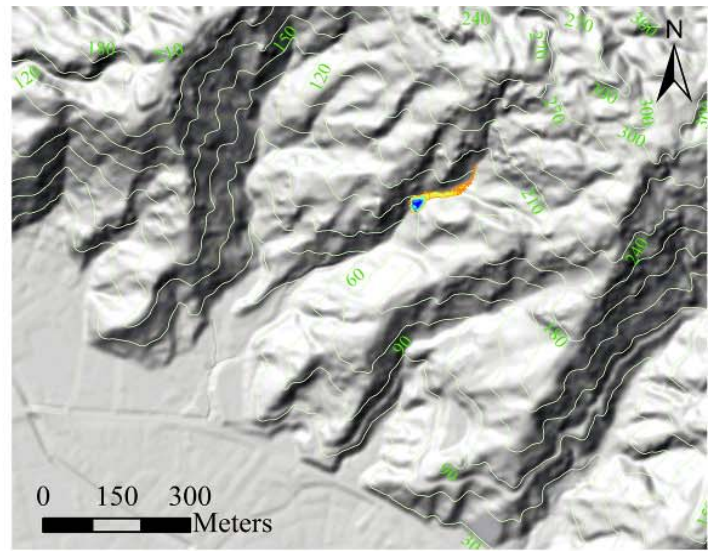

(b)

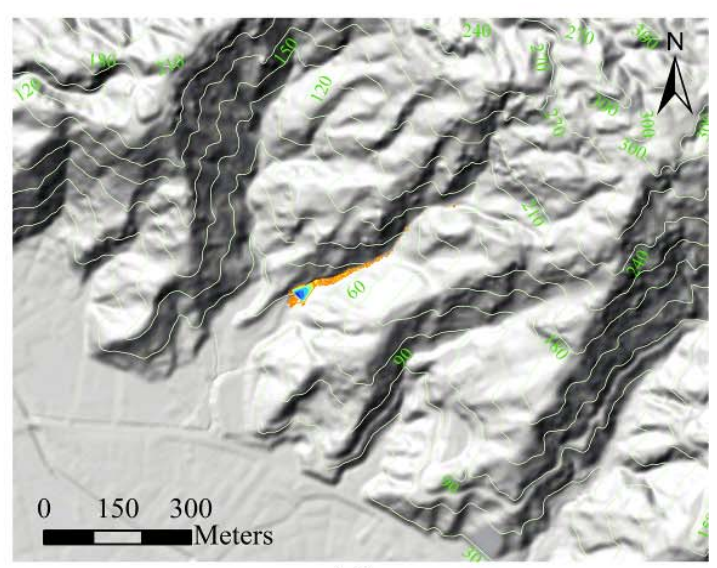

(d)

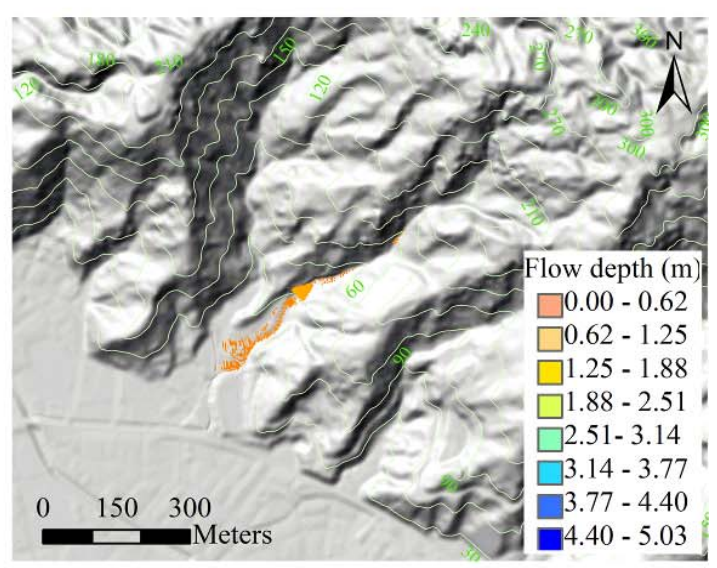

(f)

Figure 6 Movements and affected regions in different times ((a) 2s, (b) 30s, (c) 94s, (d) 110s, (e) 150s, (f) 214s).

\section{Conclusion}

The results of numerical simulation and GIS technology provide a good platform for coupling a numerical model of a debris flow. As rater grid networks of a digital elevation model in GIS were used as the finite difference mesh, the governing equations were solved numerically using Leap-frog difference scheme. All the input and output data are processed in GIS. As a real case study, the model achieved reasonable results in comparison with field investigation. The conclusions and advantages of this method are:

(1) The numerical model describes debris flow covering both erosion and deposition processes. Comparing with the simulation results with field 


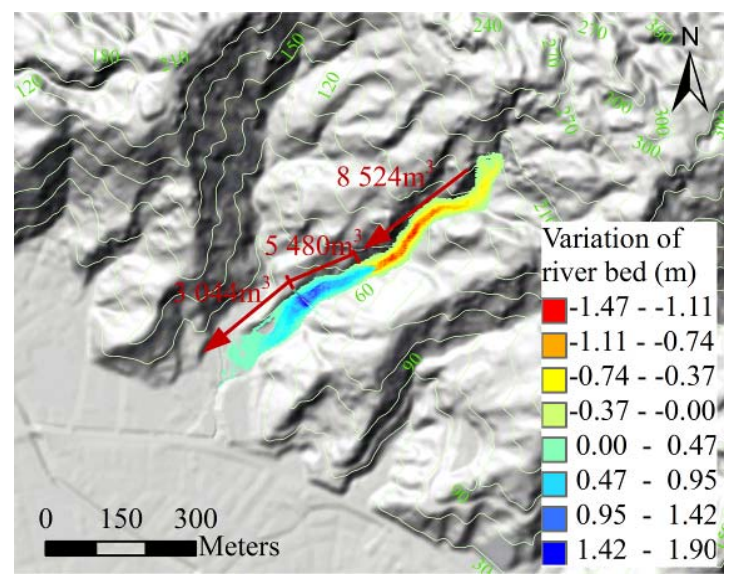

Figure 7 Variation of river bed (The equations of Nakagawa et al. 2003 were used to calculate equilibrium concentration)

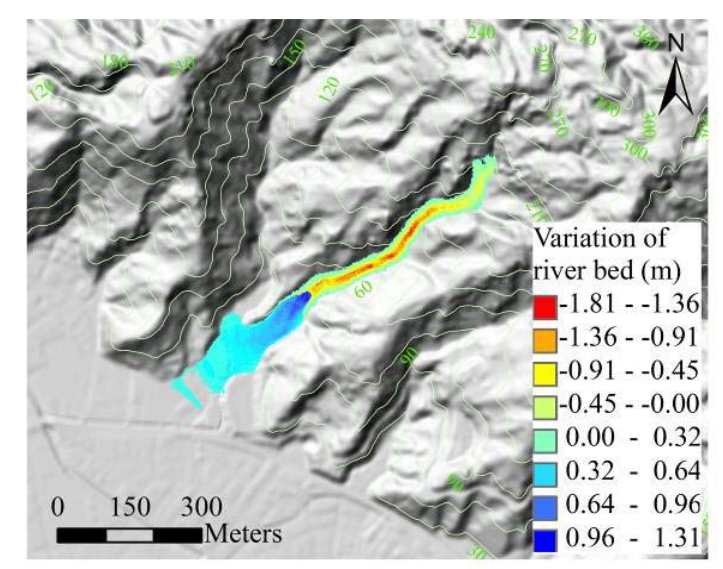

(a)

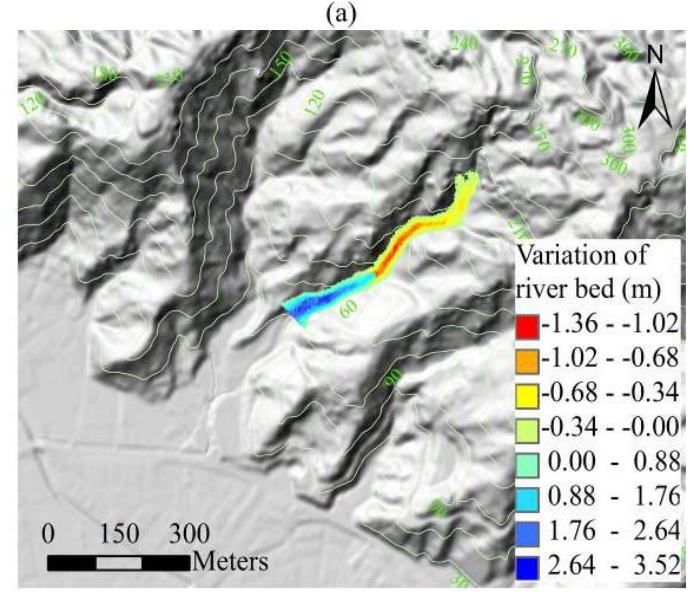

(b)

Figure 8 Flooded area (a) no dam, (b) dam height increased $1.62 \mathrm{~m}$

investigation and other models, it shows that this model can well simulate the erosion and deposition.

(2) The pre-processing and post-processing of numerical simulation are easily realized by using GIS technology. The grid networks for computation

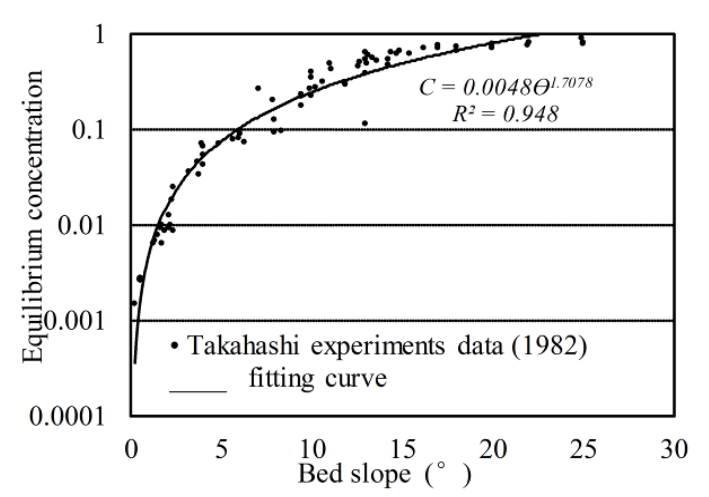

Figure 9 Fitting curve of equilibrium concentration getting from Takahashi experiments data (1982)

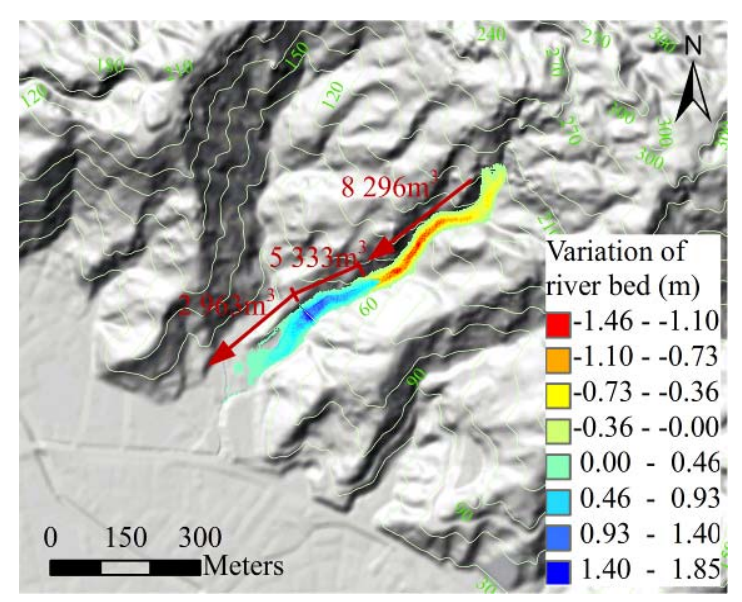

Figure 10 Variation of river bed (Use fitting Eq.to calculate equilibrium concentration)

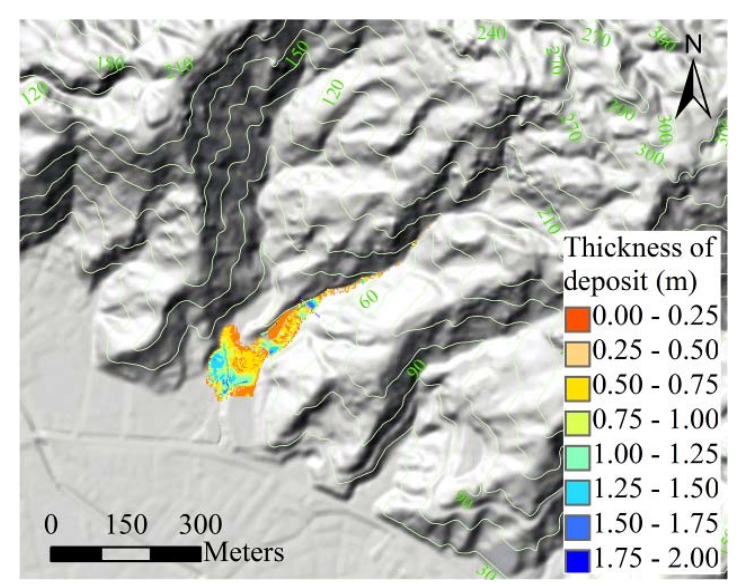

Figure 11 Thickness of deposit by fixed bed model (the model proposed by Wang et al. 2008)

can extracted from GIS, and the simulation results can be converted to GIS to form the hazard map for debris flow.

(3) This coupled model can be used to evaluate effectiveness of dam for cutting debris flow. The 
simulated results show that this method can offer a good pre-planning guideline for engineers.

(4) The simplified equilibrium concentration is easier and useful for the user.

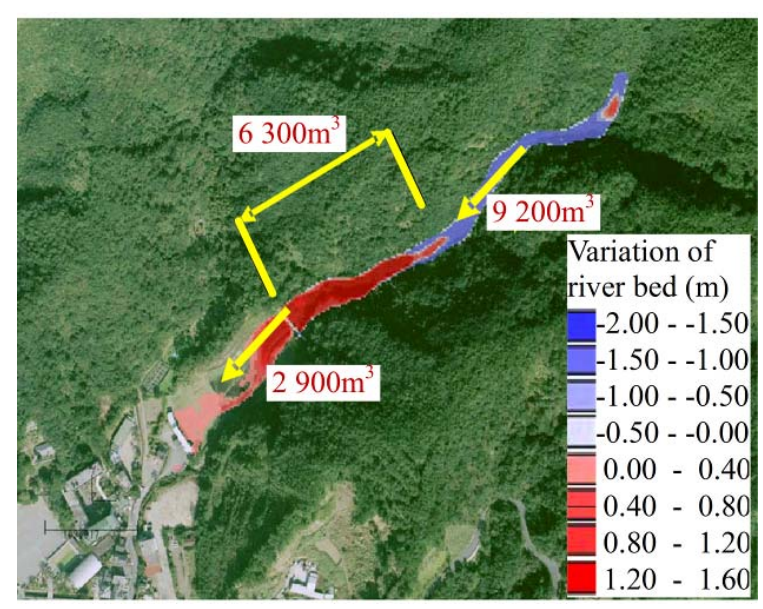

Figure 12 Variation of river bed by New-SASS model (The model proposed by Sabo and Landslide Technical Center in Japan)

\section{References}

Armanini A, Fraccarollo L, Rosatti G (2009) Two-dimensional simulation of debris flows in erodible channels. Computers \& Geosciences 35: 993-1006. Doi.org/10.1016/j.cageo.2007.11. 008.

Blahut J, Horton P, Sterlacchini P, Jaboyedoff M (2011) Debris flow hazard modelling on medium scale: Valtellina di Tirano, Italy. Natural Hazards and Earth System Sciences 10: 23792390. Doi.org/10.5194/nhess-10-2379-2010.

Brufau P, García-Navarro P, Ghilardi P, et al. (2000) 1D mathematical modelling of debris flow. Journal of Hydraulic Research 38(6): 435-446.

Cheng KY, Lin LK, Chang SY (1997) The field investigation and GIS application in a potential hazardous area of debris flow. Debris-Flow Hazards Mitigation: Mechanics, Prediction, and Assessment, Proceedings of the First International Conference, ASCE, New York. pp 83-92.

Coussot P (1994). Some considerations on debris flow rheology. In: P. Ergenzinger and K.H. Schmidt (eds.), Dynamics and Geomorphology of Mountain Rivers, Berlin German. pp 315326. Doi.org/10.1007/BFbo117848.

Sidle RC, Chigira M (2004) Landslides and debris flows strike Kyushu, Japan. Eos, Transactions, American Geophysical Union 85: 145-156. Doi.org/10.1029/2004EO150001.

Fraccarollo L, Papa M (2000) Numerical simulation of real debris-flow events. Physics and Chemistry of the Earth 25: 757-763. Doi.org/10.1016/S1464-1909(0o)ooo98-8.

Hungr O (1995) A model for the runout analysis of rapid flow slides, debris flows, and avalanches. Canadian Geotechnical Journal 32: 610-623. Doi.org/10.1139/t95-063.

Hungr O, Evans SG (1997) A dynamic model for landslides with changing mass. In: Marinos, Koukis, Tsiambaos \& Stournaras (eds.), Engineering geology and the environment, Athens, Greece. pp 719-724.

Kappes MS, Malet JP, Remaitre A, et al. (2011) Assessment of
Table 2 Comparisons of calculated results (Unit: $\mathrm{m}^{3}$ )

\begin{tabular}{l|l|l|l} 
Field investigation & $\begin{array}{l}\text { Erosion } \\
\text { volume }\end{array}$ & $\begin{array}{l}\text { Intercept } \\
\text { volume }\end{array}$ & $\begin{array}{l}\text { Deposit } \\
\text { volume }\end{array}$ \\
\hline $\begin{array}{l}\text { Fixed bed model } \\
\text { New-SASS model }\end{array}$ & $\mathbf{0}$ & 5,621 & 3,076 \\
\hline $\begin{array}{l}\text { Present coupled } \\
\text { model }\end{array}$ & 2,681 & $\mathbf{1 , 0 7 3}$ & 3,022 \\
\hline
\end{tabular}

Note: Source volume for field investigation and modeling are $5,843 \mathrm{~m}^{3}$.

\section{Acknowledgement}

This study has received financial support from the Global Environment Research Fund of Japan (S-8) and from Grants-in-Aid for Scientific Research (Scientific Research (B), 22310113, G. Chen) from Japan Society for the Promotion of Science. The first author acknowledges the support of China Scholarship Council. These financial supports are gratefully acknowledged. We thank Professor Iain Taylor from the University of British Columbia for language editing.

debris-flow susceptibility at medium-scale in the Barcelonnette Basin, France. Nature Hazards Earth System Science 11: 627-641.

Lin J, Yang MD, Lin PS (1998) An evaluation on the applications of remote sensing and GIS in the estimation system on potential debris flow. Annual Conference of Chinese Geographic Information Society (CD edition).

Lin ML, Jeng SS (1995) A preliminary study of risk assessment of debris flow using GIS. Journal of the Chinese Institute of Civil and Hydraulic Engineering 7: 475-486. (In Chinese)

Lin PS, Lin JY, Hung JC, Yang MD (2000) Risk assessment of potential debris flows using GIS. Proceedings of the Second International Conference on Debris-Flow. Taipei, Taiwan. pp 431-440.

Lai C (1991) Modelling alluvial channel flow by multimode characteristic method. Journal of Engineering Mechanics 117: 32-53. Doi.org/10.1061/(ASCE)0733-9399(1991)117:1(32).

Moore ID, Grayson RB (1991) Terrain-based catchment partitioning and runoff prediction using vector elevation data. Water Resources Researches 27: 1177-1191. Doi.org/10.1029/ 91WRooogo.

Morris PH, Williams DJ (1996) Relative celerities of mobile bed flows with finite solid concentration. Journal of Hydraulic Engineering 122: 311-315. Doi.org/10.1061/(ASCE)07339429(1996)122:6(311).

Nakagawa H, Takahashi T (1997) Estimation of a debris flow hydrograph and hazard area. In: Chen CL (eds.), Debris-Flow Hazards Mitigation: Mechanics, Prediction, and Assessment, Proceedings of first International DFHM Conference. San Francisco, CA, USA. pp 64-73.

Nakagawa H, Takahashi T, Satofuka Y (2000) A debris-flow disaster on the fan of the Harihara River, Japan. In: Wieczorek GF and Naeser ND (eds.), Debris-Flow Hazards Mitigation: Mechanics, Prediction, and Assessment, 
Proceedings of second International DFHM Conference. Taipei, Taiwan. pp 193-201.

Nakagawa H, Takahashi T, Satofuka Y, Kawaike K (2003) Numerical simulation of sediment disasters caused by heavy rainfall in Camuri Grande basin, Venezuela 1999, Proceedings of the third Conference on Debris-flow Hazards Mitigation: Mechanics, Prediction, and Assessment. pp 671-682.

Naef D, Rickenmann D, Rutschmann P, McArdell BW (1999) Comparison of friction relations for debris flows using a one dimensional finite element simulation model. Natural Hazards and Earth System Sciences 6: 155-165.

Quan Luna B, Remaitre A, van Asch TWJ, et al. (2012) Analysis of debris flow behavior with a one dimensional run - out model incorporating entrainment. In: Engineering geology, 128: 63-75.

Quan Luna B, Blahut J, van Westen CJ (2011) The application of numerical debris flow modelling for the generation of physical vulnerability curves. Natural hazards and earth system sciences 11: 2047-2060. Doi.org/10.5194/nhess-11-2047-2011.

Rickenmann D, Koch T (1997) Comparison of debris flow modelling approaches. In: Chen CL (eds.), Debris-Flow Hazards Mitigation: Mechanics, Prediction, and Assessment, Proceedings of first International DFHM Conference. ASCE, New York, USA. pp 576-585.

Shieh CL, Jan CD, Tsai YF (1996) A numerical simulation of debris flow and its applications. Natural Hazards 13: 39-54. Doi.org/10.1007/BFo0156505.

Tang C, Renger N, Yang YH, Wang GF (2011) Triggering conditions and depositional characteristics of a disastrous debris flow event in Zhouqu city, Gansu Province, northwestern China. Natural Hazards and Earth System Sciences 11: 2903-2912. Doi.org/10.5194/nhess-11-2903-2011.

Takahashi T (1982) Study on deposition of debris flows (3): Erosion of debris fan. Disaster Prevention Research Institute annuals 25 (B-2): 327-348. (In Japanese)

Takahashi T, Nakagawa H, Nishizaki T (1986) Two dimensional numerical simulation method to estimate the risk of a flood hazard caused by a river bank breach. Disaster Prevention Research Institute annuals 29 (B-2): 431-450. (In Japanese)

Takahashi T, Nakagawa H, Yamaji A (1987) Method for determination of the hazardous area due to a debris flow. Disaster Prevention Research Institute annuals 30 (B-2): 611626. (In Japanese)

Takahashi T (1991). Debris Flow, IAHR Monograph Series, A.A. Balkema: Rotterdam. Doi.org/10.1201/9780203946282.

Takahashi T, Nakagawa H, Harada T, Yamashiki Y (1992) Routing debris flows with particle segregation. Journal of Hydraulic Engineering 118: 1490-1507. Doi.org/10.1061/ (ASCE)0733-9429(1992)118:11(1490).

Takahashi T (2007). Debris Flow: Mechanics, Prediction and Countermeasures. Balkema-proceedings and monographs in engineering, water and earth sciences. pp 448.

Wang C, Li S, Esaki T (2008) GIS-based two-dimensional numerical simulation of rainfall-induced debris flow. Natural hazards and earth system sciences 8: 47-58. Doi.org/ 10.5194/nhess-8-47-2008.

Whipple KX (1997) Open channel flow of Bingham Fluids: applications on debris flow research. The Journal of Geology 105: 243-262. Doi.org/10.1086/515916.

Yoshiaki I and Akihide T (1978) Numerical simulations of flows and dispersive behaviours in southern part of lake Biwa. Disaster Prevention Research Institute Annuals 31 (B-2):293305. (In Japanese)

Zanre DDL, Needham DJ (1996) On simple waves and weak shock theory for the equations of alluvial river hydraulics. Philosophical Transactions of the Royal Society A 354: 29933054. Doi.org/10.1098/rsta.1996.0137. 